\title{
Robot-Assisted Wedge-Bronchoplastic Right Upper Lobectomy, a Case Report
}

\author{
Omar Matthieu SARSAM ${ }^{2}$, Benjamin BOTTET ${ }^{3}$, Christophe PEILLON ${ }^{4}$, Jean-Marc \\ BASTE $^{1 *}$ \\ ${ }^{1}$ Consultant thoracic and cardiovascular surgeon, University hospital of Charles Nicolle, France. \\ ${ }^{2}$ Resident doctor in thoracic surgery, University hospital of Charles Nicolle, France. \\ ${ }^{3}$ Resident doctor in thoracic surgery, University hospital of Charles Nicolle, France. \\ ${ }^{4}$ University professor in thoracic surgery -Head of department, University hospital of Charles Nicolle, France.
}

Received: January 09, 2017; Accepted: January 17, 2017; Published: January 30, 2017

*Corresponding author: Jean-Marc BASTE, consultant thoracic and cardiovascular surgeon, Department of general and thoracic surgery, Pr. PEILLON - University hospital of Charles Nicolle 1, rue de Germont 76000, Rouen, France, Tel: 0033(0)32888990; Fax: $0033(0) 232888028$; E-mail : jean-marc.baste@chu-rouen.fr

Keywords: obot-Assisted; Sleeve; Wedge-Bronchoplasty

\section{Introduction}

Lung cancer was the most fatal cancer in 2016 [1]. Surgery remains the most effective treatment for its most common type; Non-Small Cell Lung Cancer (NSCLC) [2]. Bronchoplasty and angioplasty techniques were developed in order to achieve curative treatment for tumors invading main/lobar bronchi and/or blood vessels where the patient's Pulmonary Function Tests (PFTs) contraindicate pneumonectomy [3]. However, it was shown later that performing sleeve lobectomy is preferable to pneumonectomy whenever a full resection is possible as it contributes to saving normal lung tissue, lowers postoperative complications and is as effective as pneumonectomy on an oncological level [2, 4-6].

Despite lack of supporting data, Park SY et al suggested that wedge bronchoplasty can be considering an alternative to sleeve bronchoplasty that doesn't compromise the quality of the resection [7].

Here we describe our first Robot-assisted wedgebronchoplastic right upper lobectomy using the DaVinci SI robot (intuitive surgery).

\section{Case Presentation}

A case of 65-year old male presented with repeated episodes of respiratory infections not resolving despite appropriate treatment. The patient was an active smoker of 50 pack years with a past history of alcoholism, depression and one suicidal attempt.

A contrast-enhanced chest CT scan was performed; this showed a mass of $35 \mathrm{~mm}$ in size completely obstructing the right upper lobe bronchus resulting in atelectasis along with hilar lymphadenopathies [fig 1].

In the light of these results, a bronchoscopical examination and biopsies were carried out. The histopathological analysis was in favour of squamous cell carcinoma.

A PET scan was then done; it showed hypermetabolism of the mass in question along with suspicious lymph nodes in the Bariety space with no secondary lesions elsewhere. Thus the preoperative classification was cT2aN2M0.

The pulmonary function tests results were FEV1 of $2.41 \mathrm{~L}$ (83\%) and a DCO of $89 \%$.

During the multidisplinary meeting, it was decided to operate the patient of a bronchoplastic right upper lobectomy using robot-assisted VATS.
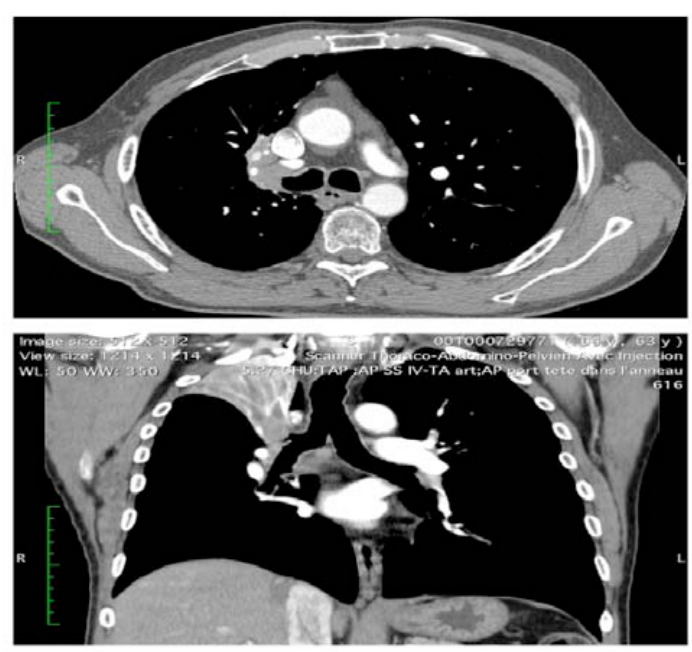

Figure 1: CT scan, axial and coronal sections showing the tumor occluding the main bronchus causing atelectasis of the right upper lobe 


\section{Operative Technique}

Patient's installation was in left lateral decubitus position with double lumen endotracheal intubation after induction. We used a 3-arms approach with an assistant utility port that was eventually enlarged to get the piece out at the end of the surgical intervention. Trocars placement was done as shown in [fig $2 \mathrm{a}, \mathrm{b}]$.

We first dissociated the triangular ligament and lymph node removal of station 9 [fig 3a, b].

Complete sub-carinal lymph nodes dissection and removal was done [fig 3c]

Dissection of the posterior part of the hilum - here we expose the right main bronchus [fig 4a].

Dissection of the anterior and the superior parts of the hilum. Visualization of the mediastinal artery, placement of a vessel loop and sectioning the artery [fig4 $\mathrm{b}$-d].

Exposure of the pulmonary artery and lymph node removal [fig5 a,b].

Controlling and sectioning the truncus anterior then the posterior segment artery (A2) [fig 5c, d].

We identify and section the superior pulmonary vein. Then we finish at the anterior fissure [fig 6]. Here the upper lobe is only hold by the bronchus.

We cut the bronchus by scissors. Samples were send for fresh frozen section examination, the results showed safe margins. We realize a direct suturing using VELOC 4/0 in 2 continuous running sutures from each end to minimize tension and achieve perfect closure. The underwater test showed no air leakage [Video1].

When the suture was completed and in order to avoid complication a pleural flap was done to cover the wedge bronchoplasty.

The tumor was extracted using the utility port.

The blood loss was less than $50 \mathrm{cc}$. Total time was 200 minutes.

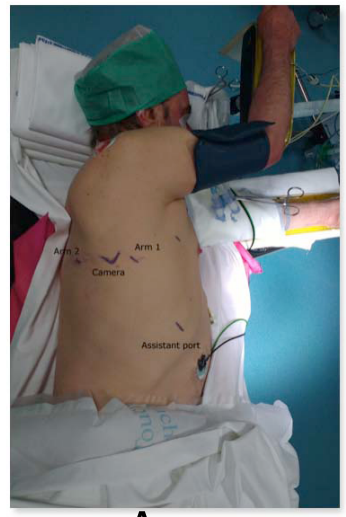

A

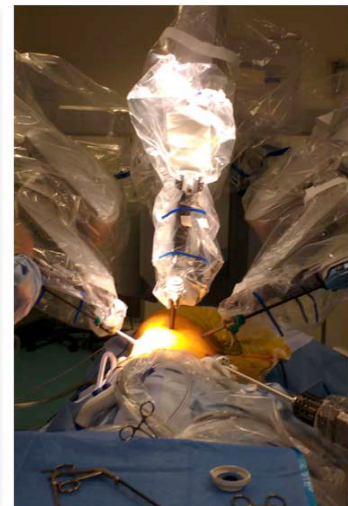

B
Figure 2a,b: patient positioning and trocars placement
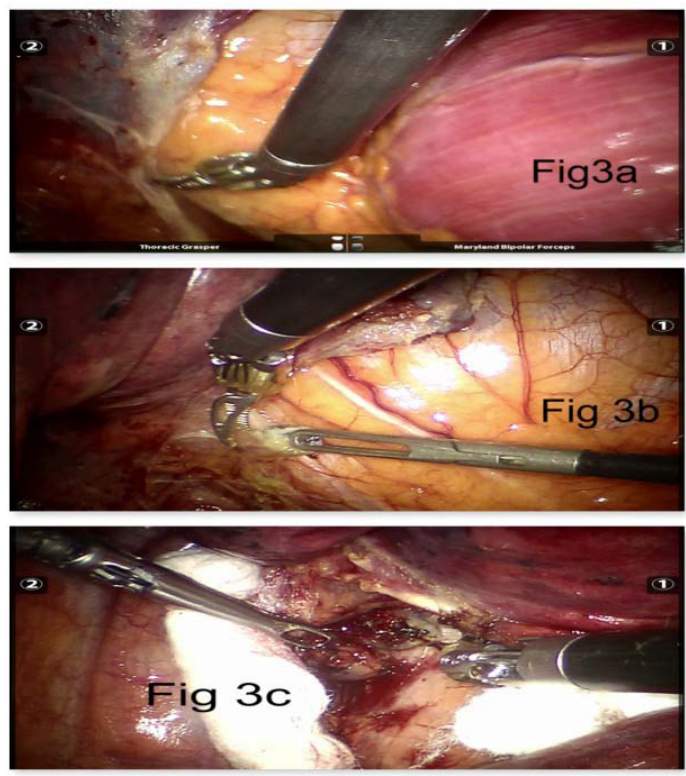

Figure 3a,b,c: a.Triangular Ligament sectioning, b. Lymph node dissection - Station 9, c.Subcarnial Lymph node dissection.
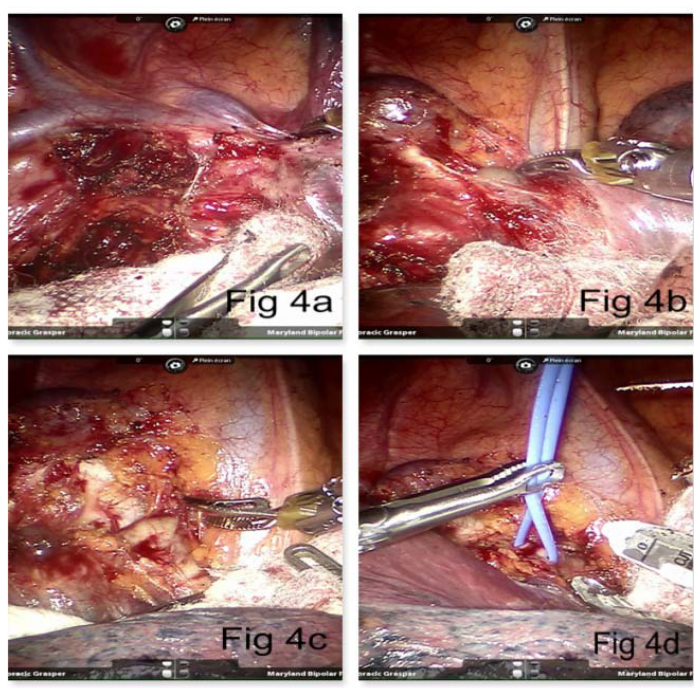

Figure 4a-d: a.Exposure of the right main bronchus.

b. Dissection of the upper part of the hilum

c. Dissection of the anterior part of the hilum and expose of the mediastinal artery.

d. Placement of a vessel loop and sectioning the mediastinal artery

\section{Postoperative}

The post-operative immediate course was marked by air leakage that lasted for 3 days. A bronchoscopy was performed at the $4^{\text {th }}$ postoperative day and showed no signs of fistula nor stricture. The thoracic drain was removed at the 5th postoperative day. The patient started having high fever at day 5 with urine examination showing a urinary tract infection necessitating treatment by antibiotics. He was later discharged on the $10^{\text {th }}$ post-operative day. 
The histopathological analysis confirmed the diagnosis of squamous cell carcinoma, the surgical resection margin on the bronchus showed carcinoma in situ (R1) and 2 lymph nodes groups were involved; $2 \mathrm{R}, 4 \mathrm{R}$. The definitive staging was pT2aN2M0.

In view of the above results, it was decided to continue the treatment with radio-chemotherapy (mediastinal radiotherapy 66 Gray in 33 sessions with 3 cycles of CARBOPLATINE AUC5 + NAVELBINE). This was very well tolerated by the patient. Regular follow-up visits with radiological examinations are scheduled periodically. He is still alive and is free of any respiratory symptoms 10 months after the surgery.

\section{Discussion}

The first open surgical sleeve lobectomy was performed by Thomas Price in 1947 for a carcinoid tumor occupying the right main bronchus [8]. It took 55 years later to read the first case report of VATS sleeve lobectomy by Santambrogio in 2002
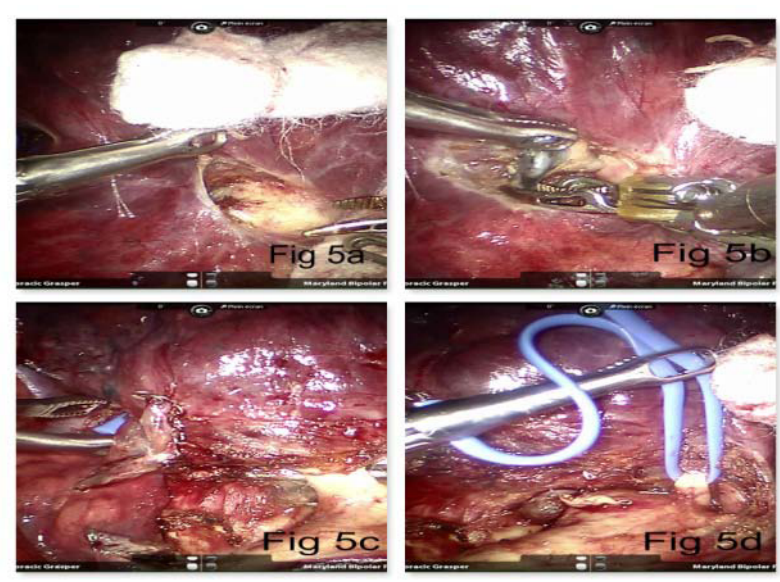

Figure 5a-d: a. Exposure of the pulmonary artery

b. Lymph node removal

c. Controlling the truncus anterior

d. Vessel loop around the A2 artery

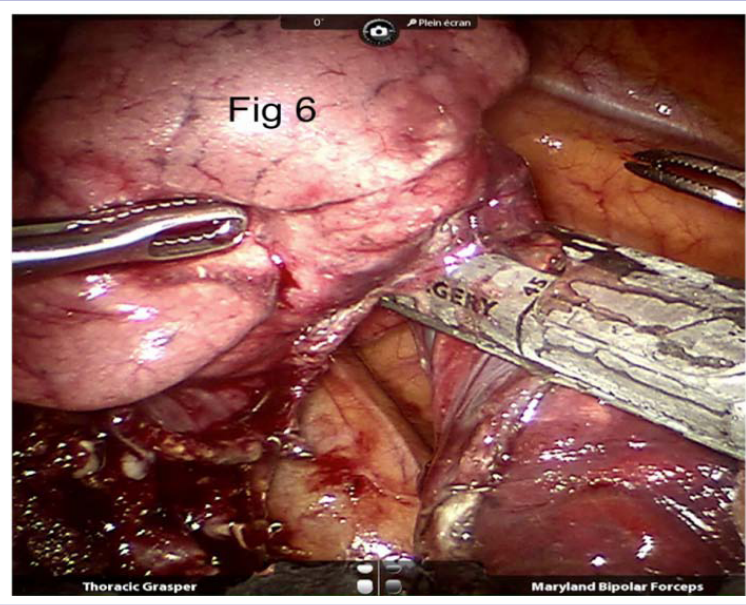

Figure 6: Finishing the anterior fissure
Video 1: Bronchoplasty and underwater test

[9]. One must highlight that before this, sleeve resections were considered contraindication to VATS [3]. 2002 also witnessed the first case report of using robotics in pulmonary surgery by Melfi [10].

We tend to notice that adopting robotics in more complicated procedure took less time than in the case of VATS. For the latter, first VATS lobectomy report goes back to 1992, that's to say a 20 -year gap till the first sleeve lobectomy. While in robotics, first sleeve bronchoplasty technique report on a fresh human cadaver came 4 years after Melfi's lobectomy [11]. However, few reports were published after that $[12,13]$.

Sleeve lobectomies are increasingly considered as the surgery of choice rather than pneumonectomy [3-6]. Minimally invasive surgery is associated with less postoperative and complications. It also helps preserving the chest wall respiratory muscles [14, 15].

Robotics offers the surgeon a wide range high quality $3 \mathrm{D}$ view of the operative field. The endowrist instrument allow for fine dissection and suturing in space-confined areas. The robot system also eliminates the surgeon's natural tremor giving us more precise and highly controlled movements [16]. This shows the possible advantage of RATS over VATS in complex lung resections.

Rouen university hospital is an accredited national and European centre for minimally invasive surgery. By the time of the operation, 320 robot-assisted major lung resection performed by our team.

Our experience showed that this procedure is feasible in a safe manner. However, despite the initial histopathological analysis results of the fresh frozen sections showing tumor safe margins on the bronchus, the definitive ones showed carcinoma-in-situ.

Thus arises the necessity of a more thorough evaluation of the oncological benefits of wedge versus sleeve bronchoplasty for central lung tumors.

\section{Conclusion}

Robotics can help us perform complex pulmonary resections 
in a safe and easier manner thanks to the endowrist instruments; nonetheless, the oncological value of wedge vs sleeve lobectomy should be studied more thoroughly.

\section{Declarations}

Omar Matthieu SARSAM and Benjamin BOTTET have no conflict of interest to declare.

Christophe PEILLON and Jean-Marc BASTE are proctors for Intuitive Surgery.

\section{References}

1. Siegel RL, Miller KD, Jemal A. Cancer statistics. 2016. CA Cancer J Clin. 2016;66(1):7-30. doi: 10.3322/caac.21332.

2. Ohta M, Sawabata N, Maeda H, Matsuda H. Efficacy and safety of tracheobronchoplasty after induction therapy for locally advanced lung cancer. J Thorac Cardiovasc Surg. 2003;125(1):96-100.

3. Predina JD, Kunkala M, Aliperti LA, Singhal AK, Singhal S. Sleeve lobectomy: current indications and future directions. Ann Thorac Cardiovasc Surg. 2010;16(5):310-318.

4. Ma Z, Dong A, Fan J, Cheng H. Does sleeve lobectomy concomitant with or without pulmonary artery reconstruction (double sleeve) have favorable results for non-small cell lung cancer compared with pneumonectomy? A meta-analysis. Eur J Cardiothorac Surg. 2007;32(1):20-28.

5. Maurizi G, D’Andrilli A, Anile M, Ciccone AM, Ibrahim M, Venuta F, et al. Sleeve lobectomy compared with pneumonectomy after induction therapy for non-small-cell lung cancer. J Thorac Oncol. 2013;8(5):637643. doi: 10.1097/JT0.0b013e318286d145.

6. Okada M, Yamagishi H, Satake S, Matsuoka H, Miyamoto Y, Yoshimura $\mathrm{M}$, et al. Survival related to lymph node involvement in lung cancer after sleeve lobectomy compared with pneumonectomy. J Thorac Cardiovasc Surg. 2000;119(4 Pt 1):814-819.

7. Park SY, Lee H-S, Jang H-J, Joo J, Kim MS, Lee JM, et al. Wedge bronchoplastic lobectomy for non-small cell lung cancer as an alternative to sleeve lobectomy. J Thorac Cardiovasc Surg. 2012;143(4):825-831.e3. doi: 10.1016/j.jtcvs.2011.10.057.

8. Thomas CP. Conservative resection of the bronchial tree. J R Coll Surg Edinb. 1956;1(3):169-186.

9. Santambrogio L, Cioffi U, De Simone M, Rosso L, Ferrero S, Giunta A. Video-assisted sleeve lobectomy for mucoepidermoid carcinoma of the left lower lobar bronchus: a case report. Chest. 2002;121(2):635636.

10. Melfi FMA, Menconi GF, Mariani AM, Angeletti CA. Early experience with robotic technology for thoracoscopic surgery. Eur J CardioThorac Surg Off J Eur Assoc Cardio-Thorac Surg. 2002;21(5):864-868.

11. Ishikawa N, Sun YS, Nifong LW, Chitwood WR, Oda M, Ohta Y, et al. Thoracoscopic robot-assisted bronchoplasty. Surg Endosc. 2006;20(11):1782-1783.

12. Nakamura H, Taniguchi Y, Miwa K, Fujioka S, Matsuoka Y, Kubouchi Y. A successful case of robotic bronchoplastic lobectomy for lung cancer. Ann Thorac Cardiovasc Surg. 2013;19(6):478-480.

13. Schmid T, Augustin F, Kainz G, Pratschke J, Bodner J. Hybrid videoassisted thoracic surgery-robotic minimally invasive right upper lobe sleeve lobectomy. Ann Thorac Surg. 2011;91(6):1961-5. doi: 10.1016/j.athoracsur.2010.08.079.

14. Nomori H, Horio H, Fuyuno G, Kobayashi R, Yashima H. Respiratory muscle strength after lung resection with special reference to age and procedures of thoracotomy. Eur J Cardiothorac Surg. 1996;10(5):352358.

15.Zhang L, Gao S. Robot-assisted thoracic surgery versus open thoracic surgery for lung cancer: a system review and meta-analysis. Int J Clin Exp Med. 2015;8(10):17804-17810.

16. Sinha R, Sanjay M, Rupa B, Kumari S. Robotic surgery in gynecology. J Minimal Access Surg. 2015;11(1):50-59. doi: 10.4103/09729941.147690 